\title{
Diversas consideraciones sobre las competencias locales
}

\author{
Fernando Fernández-Figueroa Guerrero \\ Vicesecretario General de la Excma. Diputación Provincial de Sevilla
}

Sumario: I. LA REGULACIÓN POSITIVA ACTUAL DE LAS COMPETENCIAS LOCALES Y SU MODULACIÓN JURISPRUDENCIAL: 1. El marco básico: la Ley 7/1985, de 2 de abril: 1.1. Competencias municipales. 1.2. Competencias provinciales. 2. Los marcos sectoriales: la legislación sectorial estatal y autonómica. II. EL PRESENTE Y EL FUTURO DE LAS COMPETENCIAS LOCALES: UNA DIFICIL PREDICCIÓN. III. CONSIDERACIONES PRÁCTICAS DE LA LABOR JURISDICCIONAL ANTE CONFLICTOS POR EJERCICIO DE COMPETENCIAS LOCALES.

Lo municipal tiene esencia y contenido especificos, lo municipal posee vitalidad propia, savia propia, modalidades propias, medios propios, $f$ nes propios. Es un árbol cuyas raices, tronco, ramaje, flores y frutos son y no pueden ser más que municipales. Cada Municipalidad tiene solera y peculiaridades, necesidades y costumbres, hechos diferenciales, modo de ser y contextura. Es decir: tiene alma.

Luis MaRQués CaRBó. El Derecho Local Español, vol. I, 1957.

\section{LA REGULACIÓN POSITIVA ACTUAL DE LAS COMPETEN- CIAS LOCALES Y SU MODULACIÓN JURISPRUDENCIAL}

\section{El marco básico: la Ley $7 / 1985$, de 2 de abril}

Para comprender el significado de la Ley $7 / 1985$, de 2 de abril, como marco básico en la regulación actual de las competencias locales, es preciso hacer referencia a la importante STC de 21 de diciembre de 1989, que resolvió determinados recursos de inconstitucionalidad contra determinados preceptos de dicha Ley.

Parte la Sentencia de la genérica pero incontestable afirmación de que es al Estado al que corresponde la competencia para establecer las bases, no sólo en relación a los aspectos organizativos o institucionales de la Administración Local, sino también en relación a las competencias de los Entes locales constitucionalmente necesarios. 
El razonamiento en concreto de este Tribunal es el siguiente: Como titulares de un derecho de autonomia constitucional garantizada, las Comunidades Locales no pueden ser dejadas en lo que toca a la definición de sus competencias y la configuración de sus órganos de gobierno a la interpretación que cada Comunidad Autónoma pueda hacer de ese derecho..., por todo ello, el Tribunal Constitucional deja sentado que la garantía constitucional es de carácter general y configuradora de un modelo de Estado, y ello conduce, como consecuencia obligada, a entender que corresponde al mismo la fijación de principios o criterios básicos en materia de organización y competencia.

Ciertamente esta doctrina jurisprudencial no es novedosa. Ya la STC 76/1983, de 5 de agosto, determinaba que debía ser el legislador estatal, con carácter general y para todo tipo de materias, el que fije unos principios o bases relativos a las competencias locales, encontrando cobertura a esa encomienda estatal en el concepto mismo de «bases del régimen jurídico de las Administraciones Públicas», por cuanto dicha expresión engloba a las Administraciones Locales. A esta idea responde el art. 2.1 de la LBRL.

Así, continúa afirmando el Tribunal Constitucional en esta Sentencia, que ningün reproche de inconstitucionalidad cabe formular a la referida previsión... Corresponde al legislador estatal la fijación de los principios básicos en orden a las competencias que deba reconocerse a las Entidades locales, estableciendo, y garantizando, al fin, su derecho a intervenir en cuantos asuntos afecten directamente al circulo de sus intereses y fijando al respecto unas directrices para llevar a cabo la asignación de tales competencias, directrices que se concretan en atender, en cada caso, a las características de la actividad pública y a la capacidad de gestión de la entidad local, de acuerdo con los principios de descentralización y máxima proximidad de la gestión administrativa de los ciudadanos... se mantiene y conjuga, en efecto, un adecuado equilibrio en el ejercicio de la función constitucional encomendada al legislador estatal de garantizar los minimos competenciales que dotan de contenido y efectividad a la garantía de la autonomía local, ya que no se desciende a la fijación detallada de tales competencias, pues el propio Estado no dispone de todas ellas. De ahi que esa ulterior operación quede deferida al legislador competente por razón de la materia. Legislador, no obstante, que en el caso de las Comunidades Autónomas, no puede, con ocasión de esa concreción competencial, desconocer los criterios generales que los arts. 2.1, 25.2, 26 y 36 de la misma LBRL han establecido.

Una vez analizado el ámbito interpretativo del marco básico del régimen competencial local, con su correspondiente modulación jurisprudencial, se hace preciso determinar, a un nivel de mayor concreción, la verdadera y efecti- 
va distribución de competencias que la LBRL determina para los Entes locales, partiendo para ello de su propio articulado.

Los redactores de la Ley adquirieron clara conciencia del problema de la atribución de competencias a los entes locales y así lo pusieron de manifiesto en la Exposición de Motivos que la acompaña, en la que, tras declarar que se trata de obtener «cuando menos, un mínimo común denominador en cuanto al contenido de ... (la) autonomía», confiesan "la imposibilidad material, en todo caso, de la definición cabal y suficiente de las competencias locales en todos y cada uno de los sectores de intervención potencial de la Administración local desde la legislación de régimen local».

Esta declaración de impotencia se plasma en la redacción del art. 2 de la LBRL ya transcrito. Manifestación, por otra parte, llena de buenos propósitos, pero carente de relevancia jurídica, puesto que el precepto reproducido no podrá vincular al legislador estatal ni autonómico competente para legislar en los sectores a que se refiere. Y que, además, no precisa -ni podía hacerlo- el tipo de competencia que habrá de atribuirse a los entes locales. Se trata, en definitiva, de llamar la atención sobre la necesidad de que aquellos reconozcan a dichos entes algún tipo de participación en las materias que regulen.

Congruentemente con ello, señala el art. 7.1 de la LBRL que «las competencias de las entidades locales son propias o atribuidas por delegaciónı. Clasificación, por lo demás, insuficiente. Pues ya sabemos que, junto a estas dos formas de atribución de competencias, existen otras muchas en el Derecho vigente, e incluso alguna de ellas encuentra eco en la propia Ley: así, el art. 37, relativo a las Provincias, establece que «las Comunidades Autónomas podrán delegar competencias en las Diputaciones, así como encomendar a éstas la gestión ordinaria de servicios propios en los términos previstos en los Estatutos correspondientes....». Desdoblamiento que, extraña e incoherentemente, no se establece para los Municipios.

La única virtualidad que cabe atribuir al citado art. 7.1 es la de que, en primer lugar, con términos por otra parte inadecuados, establece una suerte de reserva legal en este terreno, en cuanto declara que «las competencias propias de los Municipios, las Provincias y las Islas y demás entidades locales territoriales sólo podrán ser determinadas por Ley». Lo que excluye la posibilidad de que, según la interpretación habitual en el tema, puede entenderse que la norma especial -aunque sea de carácter reglamentario- reguladora de un concreto sector de intervención no puede ser derogada por las normas generales delimitadoras de la competencia local. 
Además, dicho artículo establece netamente la diferenciación entre la situación en que los entes locales se encuentran cuando ejercitan las competencias propias y las impropias —aunque se refiere sólo a las delegadas-. En el primer caso sólo podrán verse afectados por las facultades de coordinación que la Ley atribuya al Estado o a las CC.AA.; mientras que en el supuesto de competencias impropias habrá que estar a los términos en que se atribuyan.

Aparte de estos principios generales, en la LBRL se ha intentado una mayor profundización. Así, en cuanto al Municipio:

1. Establece su capacidad general para la gestión de sus intereses.

2. Enumera una serie de fines o materias en los que ejercerá competencias en todo caso (art. 25.2), pero sin especificar de qué clase de competencias se trata. Por lo que habrá que estar a lo que disponga el legislador estatal o autonómico.

3. En rigor, las únicas competencias que la LBRL contempla y que pueden considerarse propias del Municipio son las que relaciona el art. 26, relativo a lo que se considera como servicios mínimos.

4. Por último, el art. 27 se refiere a las funciones delegadas de los municipios, con olvido de las transferidas o instrumentales que, en cambio, sí se citan en cuanto a la Provincia. La especial sensibilidad por la configuración de las Provincias en la Constitución ha determinado que la LBRL prestase a esta materia una atención singular. Así, se consideran fines propios y específicos de la Provincia:

a) Garantizar los principios de solidaridad y equilibrio intermunicipales en el marco de la política económica y totalidad del territorio provincial de los servicios de competencia municipal.

b) Partiendo de estas premisas, son competencias propias de la Diputación las reflejadas en el art. 36 de la LBRL. Además, las CC.AA. y el Estado podrán delegar competencias en las Diputaciones, así como encomendar a éstas la gestión ordinaria de servicios propios en los términos previstos en los Estatutos correspondientes.

Dedúcese de lo expuesto que aparece en la LBRL una preocupación por atenerse a la doble vertiente con que el Tribunal Constitucional consagró el carácter necesario de la Provincia. Puesto que, si por un lado se respeta su existencia, de otro se reducen al mínimo sus competencias. Sin perjuicio de la posibilidad que se establece de que la legislación especial incremente el cúmulo de aquellas funciones que se relacionan como propias, o que se utilice a la 
Diputación para la prestación de los servicios estatales o autonómicos. Como resumen de cuanto acabamos de exponer, tenemos:

1. La LBRL establece una capacidad general de los Municipios y Provincias para la satisfacción de sus respectivos intereses.

2. Las competencias propias de ambos entes aparecen deficientemente delimitadas, en particular, en cuanto al Municipio, por lo que habrá que estar, una vez más, a la legislación especial, estatal o autonómica.

3. Se introduce la importante innovación de reservar a la Ley la alteración del carácter de las competencias que la LBRL enumera como propias.

4. Se consagra el derecho de los Municipios y Provincias a intervenir en cuantos asuntos les afecten directamente. Intervención que no habrá de traducirse necesariamente en la atribución de una competencia propia y que, además, no podrá ser desconocida por las normas con rango de ley.

5. Ambos entes podrán, además, aunque ello se expresa de forma incongruente e insuficiente, ejercer funciones mediante delegación o desconcentración. En cuyo caso el sujeto público a quien tales funciones corresponden podrá interferir el ejercicio de las mismas, en los términos que la Ley establezca.

La primera operación para la delimitación de las competencias locales ha sido establecer las materias concretas sobre las que los Entes locales han de ejercer todas las competencias, o buena parte de éstas, con el carácter de servicios mínimos (art. 26 LBRL). Y, en segundo lugar, abordár la lista, no exhaustiva, de materias en las que el legislador de régimen local considere que existe implicado un interés local (art. 25.2 y 3 LBRL). Serán, luego, los legisladores - estatal o autonómico- de leyes sectoriales los que delimitarán el cuadro de funciones que corresponderá ejercer, sobre la materia regulada en cada caso, a los Entes locales - Municipios, Provincias, etc.-.

Frente a la tesis de Parejo, en el sentido de que las competencias locales es tema exclusivo de la legislación sectorial —estatal o autonómica-, MuÑoz MACHADO sostiene que la Constitución no permite semejante conclusión:

1. Porque al régimen local, a que se refiere el art. 148.1.1. ${ }^{\text {a }}$, se le asigna un contenido tradicional.

2. $\quad$ Porque la STC de 28 de julio de 1981 exige que el Estado dicte una Ley de régimen local que fije uprincipios o criterios básicos en materia de organización y competencia de general aplicación en todo el Estado». 
3. Porque muchos Estatutos de Autonomía reconocen que sea el Estado el que fije dichas competencias locales.

Teniendo en cuenta que ha de resolverse en forma armónica la tensión, $\mathrm{Mu}$ NOZ MACHADO sienta los siguientes criterios para la delimitación de las competencias locales:

1. Que la Ley estatal de régimen local ha de contener una relación básica de materias operando como se ha hecho tradicionalmente, ya que la Constitución no distingue entre organización y régimen jurídico, de una parte, y competencias, de otra.

2. Que esta lista básica de materias exige una segunda operación de delimitación de funciones o atribuciones locales sobre cada una de las materias de la lista básica, operación que corresponderá generalmente a las CC.AA., a las que se les ha otorgado la mayoría de las materias tradicionalmente locales.

3. La dualidad de operaciones en la concreción de las competencias se justifica porque es el Estado el que ha de fijar el contenido esencial de la garantía institucional de la autonomía local, marcando las materias o sectores de la actividad pública que son de interés local. Si las leyes sectoriales no atribuyen, luego, a los Entes locales, competencia alguna en estas materias se producirá una lesión evidente de esa garantía institucional.

4. Las Leyes autonómicas de desarrollo del régimen local general podrán, asimismo, concretar el alcance de las materias locales básicas, e incluso, en algunos casos, como en el de creación de entes locales nuevos, establecerlas ex novo, si no lo ha hecho ya el legislador estatal. Todo ello, sin perjuicio de la delimitación competencial por leyes sectoriales.

5. Las competencias atribuidas a los entes locales pueden ser propias, por delegación o, en una posición intermedia, propias sometidas a directiva. La cualificación de la modalidad corresponderá, por supuesto, a la legislación sectorial por razón de la materia que se trate.

\subsection{Competencias municipales}

Sin perjuicio de lo analizado en diversos artículos de otras tantas disposiciones respecto a las competencias de los municipios, el núcleo de su regulación básica lo encontramos en los arts. 25 a 28 de la LBRL. En efecto, sin separarse de antecedentes legislativos, el art. 25 parte del reconocimiento de una capacidad genérica de actuación para promover actividades y prestar servi- 
cios que afecten a las necesidades de la comunidad vecinal. De conformidad con esta afirmación, en principio, las competencias municipales serían ilimitadas, sin más límite que la propia capacidad de gestión para afrontarlas, pues, como ya dijimos con anterioridad, es prácticamente imposible encontrar un ámbito competencial que no afecte de forma directa o indirecta a los intereses vecinales 1 .

Sin perjuicio de esta capacidad genérica, tampoco puede desconocerse que la habilitación competencial municipal es limitada, en tanto en cuanto le está vedado al Municipio invadir competencias del Estado, Comunidades Autónomas y otros entes públicos, así como atentar contra los intereses supramunicipales. Si esta afirmación se contiene en el art. 10.1 LBRL, en los arts. 61 a 67 se determinan los medios de reacción o defensa estatales o autonómicos frente a invasiones competenciales municipales o atentados graves al interés general.

La LBRL, en concordancia con las Sentencias del Tribunal Constitucional ya estudiadas, enumera una serie de materias en las que, por afectar directamente a los intereses municipales, resulta necesaria la intervención del Municipio y que constituye la garantía mínima de la autonomía municipal sin perjuicio de que sea la legislación sectorial estatal o autonómica la que en virtud del principio de reserva de Ley de los arts. 2 y 5.b) LBRL determinen concretamente el alcance de tales competencias y el modo de su ejercicio. El legislador ordinario, consciente del lapso de tiempo que transcurriría hasta que aquellas sectoriales se promulgaren, introdujo la Disposición Transitoria Segunda (en la LBRL) y en la Disposición Transitoria Primera (en el TR) la declaración genérica de que «en tanto las leyes sectoriales no dispongan otra cosa, los municipios, las provincias y las islas conservarán las competencias que les atribuye la legislación sectorial vigente en la fecha de entrada en vigor de esta Ley»). Y termina la DT Segunda con una habilitación genérica en el sentido de que los Municipios ostentarán, además, en las materias a que se refiere el art. 28 de esta Ley, cuantas competencias de ejecución no se encuentren conferidas por dicha legislación sectorial a otras Administraciones Públicas.

Si la anterior exposición se refiere con exclusividad al art. 25, la LBRL, consciente de la dificultad de alcanzar un grado óptimo de desarrollo compe-

1 Un ejemplo de superposición de los «intereses nacionales» sobre los municipales, a pesar de reconocerlos expresamente en la sentencia (se refiere a «indudable presencia de un interés municipal en la materias) lo encontramos en la conocida STS de 15 de junio de 1993 (RA 4426/1993), en relación con el campo de tiro de Anchuras (Ciudad Real), donde se declaró nula una Ordenanza Municipal que regulaba determinadas actuaciones que debian respetarse en la utilización del Polígono de Tiro, por atribuirse el Ayuntamiento competencias que contradicen, y no son compatibles, con las estatales establecidas en la normativa sectorial aplicable a una zona declarada de interés para la Defensa Nacional. 
tencial en todas y cada una de las materias que cita, en su art. 26 selecciona, entre tantas competencias, determinados servicios que por su naturaleza básica y elemental para la ciudadanía deben ser atendidos con carácter obligatorio. Obligatoriedad que es exigible incluso por los vecinos en virtud del art. $18 \mathrm{del}$ mismo texto legal.

Es interesante destacar los diferentes niveles en que se clasifican los municipios, atendiendo al número de habitantes para exigirles determinados servicios o «realización de competencias» mínimas en cada uno de ellos y que se van incrementando de forma paralela al número de habitantes del municipio. Por último, es interesante resaltar la posibilidad de que los pequeños Municipios imposibilitados de establecer y prestar algunos de estos servicios, a pesar de su carácter esencial, puedan solicitar la dispensa de su prestación a la Comunidad Autónoma, pero sin olvidar el precepto del papel que en esta materia debe desempeñar la Provincia mediante funciones de asistencia y auxilio en la prestación de estos servicios ${ }^{2}$.

Por tanto, de la misma manera que el art. 25.2 establece una orden al legislador sectorial, la LBRL en el art. 26 determina unos «estándares» o niveles mínimos de prestación de servicios públicos fundamentales en todos los municipios del territorio español (art. 158.1 CE), asignando, a su vez, la responsabilidad de sus prestaciones a los propios municipios. Por ello, consciente de la incapacidad de gestión de muchos de ellos, prevé $a b$ initio la posibilidad de la asociación para su prestación. Pero lo importante es que al imponerse al Municipio la prestación de estos servicios mínimos o esenciales se le está asignando, simultáneamente, competencias sobre esas materias; competencias que, en palabras de BALLESTEROS FERNÁNDEZ ${ }^{3}$, constituyen el núcleo irreducible de la autonomía local indisponible por el legislador sectorial estatal y autonómico. Sin embargo, al determinar las competencias, el art. 26 utiliza expresiones tan genéricas como Protección Civil, Protección del Medio Ambiente, etc., no debiendo entenderse en estos supuestos concretos que el municipio asume la totalidad de la competencia decisoria sobre la materia; como ya indicábamos en el inicio de este estudio, en otros supuestos la competencia no supone una actividad prestacional (Servicio Público) por parte del Municipio, como es el caso del acceso a los núcleos de población, control de alimentos y bebidas o pavimentación de vías públicas.

2 Cabria preguntarse por qué debe solicitar la dispensa a la Comunidad Autónoma y no a la Diputación Provincial respectiva.

3 A. BAllesteros Fernández, Mamual de Administración Local, Comares, 1994. Para mayor profundidad, J. MIR Y BAGo, El sistema español de competencias locales, Madrid 1991. 
Tampoco podemos desconocer que la enumeración de servicios obligatorios del art. 26 de la LBRL coincide prácticamente con los denominados servicios esenciales reservados a los Entes locales por el art. 86.3 LBRL. Por ello, hay que entender que el art. 26 contiene un mandato dirigido al legislador sectorial para que atribuya al Municipio competencias en estas materias, y a las autoridades municipales para que ejerzan las competencias referidas a las materias en dicho precepto indicadas, en cuyo ejercicio competencial podrán establecer una organización prestadora de servicios, que tendrán la calificación de servicios públicos (art. $85 \mathrm{LBRL}$ ), pero que se efectuará en régimen de libre concurrencia con la empresa privada (bibliotecas, mercados, por ejemplo), a menos que el Municipio, además, haga efectiva la reserva de los servicios esenciales establecidos por el art. 86, lo que le permite asumir la titularidad del sector de la actividad con carácter exclusivo y excluyente de la iniciativa privada.

El tercer precepto que analizamos, es decir, el art. 27 LBRL permite la delegación de competencias por parte de la Administración del Estado, de las Comunidades Autónomas y otras Entidades locales a los Municipios siempre que se mejore la eficacia de la gestión pública y se alcance una mayor participación ciudadana. Sin entrar en la problemática que surgió en relación con este tipo de delegaciones de competencias, lo cierto y verdad es que la LBRL, al regular esta materia, ha evitado entrar en controversias, limitándose a admitir, al desarrollar los arts. 27 a 37, la posibilidad de que se delegue el ejercicio de competencias, pero sin aludir a la desconcentración de funciones o a la transferencia de la titularidad de las mismas. Esta misma impresión se deduce del texto de los arts. 66 y 67 del TR. Lo importante es que la delegación puede tener su origen tanto en el Estado como en las CC.AA., como en otros Entes locales, siendo competencia del Pleno Municipal (art. 22.2.g) LBRL) la aceptación de la delegación por el Municipio interesado. También se prevé la posibilidad de que la delegación se imponga obligatoriamente por Ley, en la que deberán constar los incrementos de medios económicos que compense la carga que la delegación implica.

El sistema competencial municipal lo cierra la LBRL con el art. 28. Si con la autorización de la delegación los municipios podrán realizar actos de ejecución de funciones que corresponden a competencias atribuidas en principio al Estado y a las CC.AA., se estaría produciendo un acotamiento, aunque no muy rígido, de las posibilidades de actuación municipales. Por ello, el art. 28 deja abiertas las puertas a un intervencionismo complementario de los Municipios en otras materias que afectan directamente a los ciudadanos, y que, como viene ocurriendo, deberán ser concretadas por las leyes sectoriales específicas. Sin embargo, del carácter de complementariedad se deduce que serán intervenciones puntuales o concretas frente a las competencias cuasitotalizadoras que permanece- 
rán en el Estado o en las CC.AA., de conformidad con la distribución competencial constitucional.

No podemos concluir la exposición de las competencias municipales sin hacer referencia a sus medios de ejecución. Resumiendo el parecer de BALLESTEROSFER. NÁNDEZ ${ }^{4}$, en esta materia podemos manifestar que, como ya hemos expuesto con anterioridad, la intervención que las leyes sectoriales atribuyen o atribuirán al Municipio en un ámbito competencial determinado no exigen en todo caso el establecimiento de un servicio público, sino que el fin que se busca al atribuir la competencia local puede conseguirse con medidas de policía $y / o$ fomento en la trilogía particular de JORDANA DE POZAS

Es el art. 84 LBRL el que habilita a las Corporaciones Locales para «intervenir la actividad de los ciudadanos a través de los siguientes medios: ordenanzas y bandos; sometimiento a previa licencia y otros actos de control preventivo; órdenes individuales constitutivas de mandato para la ejecución de un acto o la prohibición del mismo". Señalando el art. 1 del Reglamento de Servicios de las Corporaciones Locales de 1955 que los Ayuntamientos podrán intervenir la actividad de sus administrados, «en el ejercicio de la función de policía cuando existiere perturbación o peligro de perturbación grave de la tranquilidad, seguridad, salubridad o moralidad ciudadanas, con el fin de restablecerlas o conservarlas; en materia de subsistencias, además, para asegurar el abasto de los artículos de consumo de primera necesidad, la calidad de los ofrecidos en venta, la fidelidad en el despacho de los que se expendan a peso o medida, la normalidad de los precios y la libre competencia entre los suministradores y vendedores; los planes de ordenación aprobados; en los servicios de particulares destinados al público mediante la utilización especial o privativa de bienes de dominio público, para imponer la prestación de aquéllos debidamente y bajo tarifa; y en los demás casos autorizados legalmente y por los motivos y para los fines previstos»».

\subsection{Competencias provinciales}

Al régimen competencial provincial le puede ser de aplicación todo lo expuesto con anterioridad con respecto al Municipio, sin perjuicio de que, al tratarse de entes locales territoriales distintos, se pueda predicar de la provincia una serie de peculiaridades específicas ${ }^{5}$.

\footnotetext{
4 A. BALlesteros FERNÁNDEz, Introducción al Régimen Local Español, CEMCI, 1991.

5 Para un análisis más exhaustivo, V. Bolx REjG, «Significación de la Provincia en la distribución territorial del poder por la Constitución Española», RAP, n. ${ }^{\circ} 115$, pág. 339. Asimismo, L. Morell OCAÑ , La Provincia en el sistema constitucional, Madrid 1991.
} 
El punto de partida es sin duda la consolidación de la institución provincial en el propio Texto Constitucional (art. 141) y que ha venido siendo ratificado por los diferentes Estatutos de Autonomía ${ }^{6}$. Partiendo de esa consolidación, la Provincia aparece encerrada entre dos entes de nueva creación, como son la Comunidad Autónoma y la comarca a los que, necesariamente, han de atribuirse parte de las competencias que tradicionalmente se les asignaba a la Provincia. Sin embargo, en modo alguno, puede producirse un vaciamiento completo de contenidos competenciales.

En este sentido, la STC de 28 de julio de 1981 , después de reconocer que los arts. 137 a 141 de la Constitución contienen una inequívoca garantía de la autonomía provincial, concretaba que no precisa la Constitución cuáles sean estos intereses ni cuál el haz de competencias que para atender a su gestión debe el legislador atribuir a la provincia, cunque si cabe derivar de la Constitución razones que apuntan a la posibilidad de que estos intereses provinciales $y$ las competencias que su gestión autónoma comportan han de ser inflexionados para acomodar esta pieza de nuestra estructura jurídico-politica a otras entidades autonómicas de nueva creación... es claro que, verosimilmente, una parte de las competencias que hoy se atribuyen a la provincia, e incluso de los servicios minimos cuyo aseguramiento actualmente se les impone, podrán ser atribuidos o encomendados a otras entidades territoriales, pero las nociones mismas de intereses peculiares, de competencias propias y de servicios minimos preceptivos, como elementos imprescindibles constitutivos del múcleo esencial de la Institución constitucionalmente garantizada, han de ser considerados como bases que no cabe ignorar al legislar sobre la materia.

La LBRL tiene en sus arts. 31,36 y 37 los soportes para estudiar el sistema competencial provincial, determinando el primero de estos preceptos unas funciones mínimas de la provincia, cuando señala como sus fines propios y específicos «el garantizar los principios de solidaridad y equilibrio intermunicipales, en el marco de la política económica y social, y, en particular: a) Asegurar la prestación integral y adecuada en la totalidad del territorio provincial de los servicios de competencia municipal. b) Participar en la coordinación de la Administración Local con la de la Comunidad Autónoma y la del Estado». Para la consecución de dichos fines prevé la Ley la atribución de competencias que se determinan en el art. 36.

Entrando en el análisis del art. 36, en el que se determinan las competencias propias de la Diputación, hemos de observar cómo se ha producido un mantenimiento y herencia del régimen competencial que reconocían los arts. 245 a

6 Estatuto de Andalucia, art. 4.1; Comunidad Valenciana, art. 47.1; Castilla-La Mancha, art. 30.1; Castilla y León, art. 19.2. 
254 de la Ley de Régimen Local derogada, calificadas entonces como obligaciones mínimas. Sin embargo, existe una extraña coincidencia entre la regulación de materias del art. 243 de la derogada LRL con la contenida en el art. 148.1 CE, que marca los mínimos competenciales autonómicos. De modo que si las Comunidades Autónomas tienen competencias legislativas, así como las ejecutivas anteriormente atribuidas al Estado, sobre la mayor parte de las materias en que hasta ahora se ha desenvuelto el ámbito de actuación provincial, es evidente que cuando alguna Comunidad legisle sobre régimen local o apruebe alguna ley sectorial reguladora de alguna materia concreta, podrá efectuar una redistribución de competencias en función de los intereses respectivos entre ella misma y las Corporaciones Locales de su territorio. Sin embargo, «esta potestad legislativa, estatal o autonómica no es, no obstante, absolutamente ilimitada, sino que encuentra un doble límite positivo y negativo, en la propia Constitución, según entiende el Tribunal Constitucional al realizar la exégesis del concepto de Autonomía Local: en el aspecto positivo exige que se dote a cada ente de todas las competencias propias y exclusivas necesarias para satisfacer el interés respectivo; y desde el negativo, los procesos de cambio en la delimitación de los respectivos intereses que la propia Constitución impone o posibilita por la aparición de las Comunidades y de las Agrupaciones de Municipios no pueden llevar, sin embargo, a menos que la Constitución sea modificada, a una desaparición de la Provincia como entidad local dotada de autonomía para la gestión de sus propios intereses ni vaciar totalmente a éstas de sus actuales funciones como entes locales, vaciamiento que implicaría una infracción de los arts. 137, 141 y 142 de la CE»?

El art. 36 reconoce, al regular las competencias propias de la Diputación en su apartado $1 .^{\circ}$, un límite insuperable que no podrá alterar ni el Estado ni las Comunidades Autónomas con legislación específica. Sin embargo, a partir de los mismos, las competencias de las provincias son flexibles y será cada $\mathrm{Co}-$ munidad Autónoma la que le dote de contenido, sin que la LBRL asegure un contenido concreto o un ámbito competencial determinado y fijado de una vez por todas, sino la preservación de una Institución en términos reconocibles para la imagen que de la misma tiene la conciencia social en cada tiempo y lugar.

El segundo apartado del art. 36 otorga un protagonismo destacado a los planes provinciales de cooperación de las obras y servicios de competencia municipal, no para garantizar las competencias propias de la Diputación en todos y cada uno de los subapartados del art. 36.1, sino, únicamente de los dos primeros, es decir, para la coordinación de los servicios municipales entre sí para la garantía de la prestación integral y adecuada a que se refiere el apartado a) del

7 El Consultor de los Ayuntamientos, ob. cit. 
número 2 del art. 31 y, en segundo lugar, la asistencia y la cooperación jurídica, económica y técnica a los Municipios, especialmente los de menor capacidad económica y de gestión ${ }^{8}$. También el precepto que estamos estudiando, para la consecución de las competencias ya vistas, obliga a la Diputación, más que le habilita, a asegurar el acceso de la población de la Provincia al conjunto de servicios mínimos de competencia municipal y la mayor eficacia y economicidad en la prestación de éstos mediante cualesquiera fórmula de asistencia y cooperación con los Municipios 9 .

\section{Los marcos sectoriales: la legislación sectorial, estatal y autonómica}

Con mayor o menor intensidad, el legislador sectorial, estatal o autonómico, ha ido dando cumplimiento al mandato contenido en el art. 25.2 LBRL en el sentido de atribuir competencias, más al Municipio que a la Provincia, sobre el elenco de materias de dicho precepto legal. Tampoco debemos olvidar, como ya se ha apuntado, que hasta tanto la legislación del Estado, como la de las Comunidades Autónomas, no alteren las competencias reconocidas a Municipios y Provincias por la legislación sectorial vigente a la entrada en vigor de la LBRL, estos entes locales conservarán las competencias que esta legislación sectorial les tenga reconocidas (DT $2 .^{a} \mathrm{LBRL}$ ).

Sin embargo, la dificultad la encontramos por la heterogénea lista de materias que enumera el art. 25.2 LBRL. En efecto, hay funciones específicas muy concretas que el legislador ordinario no podrá desconocer: promoción y gestión de viviendas, pavimentación de vías públicas urbanas, suministro de agua y alumbrado público, etc., pero existen otras materias en las que el legislador ordinario va a disponer de un amplio margen de apreciación por la vaguedad e imprecisión de los términos empleados al definirlas. De aquí que la LBRL desconfiando de este amplio margen de apreciación (pudiendo incluirse incluso

\footnotetext{
8 La Diputación Provincial mediante acuerdo plenario aprueba anualmente un Plan Provincial de Cooperación a las Obras y servicios de competencia municipal, financiados con medios propios de la Diputación, con aportaciones municipales, y con las subvenciones que acuerden las CC.AA. y el Estado con cargo a sus respectivos presupuestos [art. 36.2.a) LBRL]. Entre los efectos más importantes que se producen con su aprobación encontramos el de la implicita declaración de utilidad pública e interés social a efectos de expropiación de los bienes y derechos necesarios para la ejecución de las obras o la prestación de los servicios. Para mayor abundamiento, M." T. Carballeira RuVera, "El Plan Provincial de Cooperación a las obras y servicios de competencia municipal), Revista de Estudios de la Admón. Local y Autonómica, n. ${ }^{\text {os }}$ 255-256. Asimismo, F. MARTínez FERNÁNDEZ, "La cooperación provincial a los servicios municipales: El Plan Provincial de cooperación', Revista de Estudio de la Admón. Local y Autonómica, $\mathrm{n}^{\circ} 260$.
}

9 En esta idea de coordinaci6n, el TS en S. del 6 de abril de 1993 (RA 2673/1993) ha expresado que, de conformidad con el art. 10.1.3, «las funciones de coordinación no afectarán, en ningún caso, a la autonomia de las Entidades locales»). 
competencias delegadas sujetas a directrices y control), haya garantizado un ámbito competencial del Municipio frente a la legislación sectorial.

A continuación vamos a centrarnos en diversos ejemplos de reconocimiento de competencias a los Entes locales por legislación sectorial promulgada con posterioridad a la entrada en vigor de la LBRL, así como algún supuesto de detracción de competencias municipales, por ejemplo, en la legislación de costas.

\section{Educación}

El art. 25.2.n) LBRL determina la competencia municipal para «participar en la programación de la enseñanza y cooperar con la Administración Educativa en la creación, construcción y saneamiento de los Centros Docentes Públicos, intervenir en sus órganos de gestión y participar en la vigilancia del cumplimiento de la escolaridad obligatoria».

La LODE (Ley Orgánica 5/1985) prevé, de entre los miembros del Consejo Escolar de los centros públicos, la presencia de un Concejal o representante del Ayuntamiento. Asimismo, en su DA 2. ${ }^{a}$ preveía la cooperación de las Corporaciones Locales con las Administraciones Educativas para la creación, construcción y mantenimiento de centros públicos docentes. Esta disposición ha sido desarrollada por el RD 2274/1993, de 22 de diciembre, de cooperación de las CC.LL. con el Ministerio de Educación y Ciencia.

La LOGSE (Ley Orgánica 1/1990, de 3 de octubre) dedica toda la Disposición Adicional 17 a las competencias de los Municipios en materia educativa, destacando el que no prevea la intervención de los Entes locales en la programación de la enseñanza, y sí el deber de, por ejemplo, la conservación, mantenimiento y vigilancia de los edificios destinados a diferentes centros de educación.

\section{Protección Civil}

La Ley 2/1985, de 21 de enero, de Protección Civil, prevé la aprobación por las Corporaciones Locales de Planes Municipales de Protección Civil en los que se contengan, además de los recursos movilizables en casos de emergencia, los criterios de movilización, la estructura operativa de los servicios, etc. No cabe olvidar la específica atribución que el art. 21 de la LBRL reconoce al Alcalde en caso de catástrofe pública o calamidad. 


\section{Patrimonio histórico español}

La Ley 13/1985, de 25 de junio, partiendo de un deber de cooperación de los Ayuntamientos con los organismos competentes para la ejecución de dicha Ley (art. 7), reconoce, concretamente, la obligación municipal de redactar un plan especial de protección del área que fuere afectada por una declaración de conjunto histórico, sitio histórico o zona arqueológica como bienes de interés cultural (art. 20).

\section{Protección del consumidor}

Es el art. 41 de la Ley 26/1984, de 19 de julio, General para la Defensa de los Usuarios, el que concreta que "corresponderá a las autoridades y Corporaciones Locales promover y desarrollar la protección y defensa de los consumidores y usuarios en el ámbito de sus competencias y de acuerdo con la legislación estatal y, en su caso, de las Comunidades Autónomas, y especialmente en los siguientes aspectos: 1) Información y educación de los consumidores y usuarios, estableciendo las oficinas y servicios correspondientes, de acuerdo con las necesidades de cada localidad. 2) La inspección de los productos y servicios a que se refiere el art. 28.2 para comprobar su origen e identidad, el cumplimiento de la normativa vigente en materia de precios, etiquetado, presentación y publicidad, y los demás requisitos o signos externos que hacen referencia a sus condiciones de higiene, sanidad y seguridad. 3) La realización directa de la inspección técnica o técnico-sanitaria y de los correspondientes controles y análisis, en la medida en que cuenten con medios para su realización, o promoviendo, colaborando o facilitando su realización por otras Entidades y Organismos. 4) Apoyar y fomentar las asociaciones de consumidores y usuarios. 5) Adoptar las medidas urgentes y requerir las colaboraciones precisas en los supuestos de crisis o emergencias que afecten a la salud o seguridad de los consumidores y usuarios. 6) Ejercer la potestad sancionadora con el alcance que se determine en sus normas reguladoras».

Este precepto fue declarado conforme a la Constitución en virtud de la STC 15/1989, de 26 de enero, si bien su ámbito de aplicación y eficacia no alcanzará a aquellas Comunidades Autónomas con competencias normativas y ejecutivas en materia de protección de consumidores y usuarios, por lo que en este caso habrá de observarse lo que disponga la legislación autonómica respectiva. 


\section{Sistema Bancario}

La competencia local más evidente y tradicional en esta materia aparece regulada en la Ley 31/1985, de 2 de agosto, de Regulación de las Normas Básicas sobre Órganos Rectores de las Cajas de Ahorros (desarrollada por RD 198/1986, de 21 de marzo). En esta disposición legal se determina que las Corporaciones Locales en cuyos términos tengan abiertas oficinas las Cajas de Ahorros tienen una representación en la Asamblea General del $40 \%$ de los Consejeros ${ }^{10}$.

\section{Salubridad pública}

Es uno de los temas donde mayor y progresivo intervencionismo han asumido las Corporaciones Locales. El punto de partida lo encontramos en el art. 42 de la Ley 14/1986, de 25 de abril, General de Sanidad, cuando atribuye competencias a las Corporaciones Municipales para, entre otras, el control sanitario de industrias, actividades y servicios, transportes, ruidos y vibraciones; control sanitario de los cementerios y policía sanitaria mortuoria y la competencia, tan de moda en la actualidad, del control sanitario del medio ambiente, así como de las aguas y residuos. Recordemos que la propia LBRL atribuía competencias mínimas a los Municipios, en virtud de su población, sobre esta materia, declarando el art. 86.3 de dicho texto legal la reserva en favor de las Entidades locales de los servicios esenciales de abastecimiento y depuración de aguas; recogida, tratamiento y aprovechamiento de residuos; mataderos, mercados y lonjas centrales; y servicios mortuorios.

La Ley General de Sanidad, en un disperso articulado, reconoce otras competencias de los Entes locales en esta materia, como es el caso del art. 55.2, en el que se determina que las Corporaciones Locales que vinieran desarrollando servicios hospitalarios participarán en la gestión de los mismos.

\section{Transportes}

También constituye junto con la anterior materia uno de los supuestos tradicionales de intervención de los Entes locales. Así, el art. 113 de la Ley 16/1987, de 30 de julio, de Ordenación de los Transportes Terrestres, preceptúa que:

«1. Los Municipios serán competentes con carácter general para la gestión y ordenación de los servicios urbanos de transporte de viajeros que se lleven a cabo dentro de sus respectivos términos municipales...

10 Las SSTS de 2 de febrero, 8 de julio y 4 de noviembre de 1988 determinaron que la designación de estos representantes del Municipio o Provincia corresponde al Pleno por mayoria simple. No obstante, la STS de 10 de noviembre de 1992 atribuye la competencia al Presidente de la Corporación. 
3. Cuando los servicios a que se refiere el punto primero anterior afecten a intereses que trasciendan de los puramente municipales, las competencias de los correspondientes Ayuntamientos se ejercerán de forma coordinada con las de las Entidades de ámbito superior, según lo que en su caso establezcan las correspondientes normas estatales o de las Comunidades Autónomas.»

El Reglamento de la LOTT (aprobado por RD 1211/1990, de 28 de septiembre) insiste en esta idea de complementariedad al establecer, en su art. 141, que «las competencias municipales sobre los transportes y las actividades auxiliares y complementarias de éstos se ejercerán con sujeción a lo dispuesto en las normas sustantivas del Estado y de las Comunidades Autónomas que regulen los mismos».

De entre las competencias específicamente municipales sobre esta materia destacan las clásicas en relación con los transportes funerarios, sanitarios y otros especiales (arts. 141.5, 135 y 139); el otorgamiento de autorizaciones para la realización de servicios de transporte de viajeros de carácter interurbano en automóviles de turismo, que estará condicionado a la previa obtención de la licencia de transporte urbano expedida por el Municipio en que esté residenciado el vehículo y en el que deberá realizarse el servicio (arts. 115 y 116 LOTT y 123, 124 y 143 de su Reglamento). También debemos recordar que el art. 26 LBRL reconoce que el servicio de transporte colectivo urbano de viajeros constituye una obligación mínima para los municipios con población superior a 50.000 habitantes. A tal efecto recordemos que sigue vigente el «Reglamento de Taxis», aprobado por RD 763/1979, de 16 de marzo.

\section{Residuos sólidos}

La atribución de la competencia municipal en esta materia viene reconocida en la Ley 42/1975 (modificada por RD Legislativo 1163/1986, de 13 de junio) sobre recogida y tratamiento de los desechos y residuos sólidos urbanos, que impone, como obligación principal a los Ayuntamientos, la de hacerse cargo de todos los residuos sólidos urbanos que se produzcan en el territorio de su jurisdicción (art. 3.3). Si se tratare de productores de residuos sólidos industriales, de la construcción, o de los especiales señalados por la Ley, los Ayuntamientos podrán imponer a aquéllos la obligación de constituir depósitos o vertederos propios o proceder a su eliminación (art. 4.3). 


\section{Costas}

De la Ley 22/1988, de 28 de julio, de Costas y su Reglamento (RD 1471/1989), destacaríamos los arts. 112 y 117 . A través de estos artículos se viene a sustraer competencias municipales en materia urbanística mediante la regulación de un informe preceptivo y vinculante en favor de la Administración del Estado. Así, se dice, que concluida la tramitación del Plan Urbanístico, Norma Urbanística correspondiente, o incluso su modificación o revisión y, antes de la aprobación definitiva, la Administración Urbanística competente (pueden serlo también Entidades locales) dará traslado a la del Estado del contenido de aquél para que en el plazo de dos meses se pronuncie sobre el mismo. En caso de que el informe sea desfavorable, en aspectos de su competencia, se abrirá un período de consultas a fin de llegar a un acuerdo.

\section{Puertos}

Pero hay más. En la Ley de Puertos, en otro precepto (art. 19) se afirma expresamente que las obras de nueva construcción, reparación y conservación que se realicen en el dominio público portuario, por las autoridades portuarias, no estarán sometidas a los actos de control preventivo municipal a que se refiere el art. 84.1.b) de la Ley $7 / 1985$ por constituir, se dice, obras públicas de interés general en bloque. Aquí puede concluirse que hay una sustracción competencial, pero, ciertamente, si analizamos este tema, el tratamiento que el legislador estatal da a estas obras en el dominio público portuario también tiene su explicación en el nuevo Texto Refundido de la Ley del Suelo, pues el actual art. 244 recoge el texto del apartado $1 .^{\circ}$ del art. 180 anterior, pero le añade ciertamente una expresion que le da la vuelta al precepto y queda éste del modo siguiente: «Los actos que se promuevan por órganos de las Administraciones Públicas o entidades de Derecho público que administren bienes de aquélla, estarán igualmente sujetos a licencia municipal, si así se requiere por la legislación aplicable». Le ha dado la vuelta a la regla general, cual era la exigencia, en términos generales, del deber de sujeción a la licencia municipal.

\section{Playas}

De conformidad con el art. 53 de la ya referida Ley de Costas, la explotación de los servicios de temporada, que no exigen instalaciones fijas, sino desmontables, que puedan establecerse en las playas, corresponde al Municipio en cuyo término radiquen aquéllas, siempre que lo solicite, pudiendo realizar dicha explotación por gestión directa, manteniendo, en todo caso, el uso público de la playa. Otras referencias de esta Ley a la competencia local se re- 
cogen, por ejemplo, en la DA $5 .^{\mathrm{a}}$ en cuanto a la exigencia de concesión demanial previa a la licencia municipal de obras o funcionamiento o el art. 115, que establece:

«Las competencias municipales, en los términos previstos por la legislación que dicten las Comunidades Autónomas, podrán abarcar los siguientes extremos:

a) Informar los deslindes del dominio público marítimo-terrestre.

b) Informar las solicitudes de reservas, adscripciones, autorizaciones y concesiones, para la ocupación y el aprovechamiento del dominio público marítimo-terrestre.

c) Mantener las playas y lugares públicos de baño en las debidas condiciones de limpieza, higiene y salubridad, así como vigilar la observancia de las normas e instrucciones dictadas por la Administración del Estado sobre salvamento y seguridad de las vidas humanas.»

En esta materia sí es interesante destacar la STC 149/1991, de 4 de julio, que declaró inconstitucional el art. 118 de la Ley de Costas por no establecer limitaciones a la Administración estatal para coordinar la actuación autónoma local, y ha señalado que el informe preceptivo y vinculante de costas sólo puede referirse a sus potestades derivadas del dominio público del que es titular.

\section{Otra normativa sectorial ${ }^{11}$}

Intentar agotar todas y cada una de las referencias que a las competencias locales se realiza en la cambiante y flexible legislación administrativa sectorial es prácticamente imposible. Por ello, quedan aquí indicadas, a efecto testimonial, otras disposiciones legales donde, con mayor o menor intensidad y acierto, se reconocen competencias locales. Así:

- Seguridad ciudadana y orden público. Ley Orgánica 1/1992, de 21 de febrero, sobre protección de la seguridad ciudadana; art. 25.2.a) LBRL; Ley Orgánica 2/1986, de 13 de marzo, de Fuerzas y Cuerpos de Seguridad; RD 2816/1982, de 27 de agosto, en materia de Policía de Espectáculos Públicos y Actividades Recreativas; Ley de 30 de julio de 1959 de

11 Para completar el cuadro competencial puede consultarse de Ángel SÁNCHEZ MarTin y Rosendo SÁnChez Garcia, Gestión directa de servicios públicos locales. En particular las sociedades mercantiles municipales, CEMCI, 1993, págs. 29 y ss. 
Orden Público; RD 339/1990, de 2 de marzo, por el que se aprueba el Texto Refundido de la Ley sobre Seguridad Vial ${ }^{12}$.

- Cultura. Órdenes de 28 de febrero, 31 de marzo y 28 de diciembre de 1978 por las que se establecen el régimen de cartas culturales y convenio entre el Ministerio de Cultura y los Entes Territoriales.

- Abastecimiento de agua, alcantarillado y aguas residuales. Ley $14 / 1986$, de 25 de abril, General de Sanidad [art. 42.3.a)]; Ley 29/1985, de 2 de agosto, de Aguas y RD 849/1986, de 11 de abril, por el que se aprueba el Reglamento de dominio público hidráulico; Orden de 23 de diciembre de 1986 sobre obligación a los Ayuntamientos de obtener autorización para el vertido de aguas residuales; RD 1138/1990, de 14 de septiembre, por el que se aprueba el Reglamento Técnico-Sanitario para el abastecimiento y control de calidad de las aguas potables de consumo público ${ }^{13}$.

- Suministro de gas. Ley 10/1987, de 15 de mayo, de disposiciones básicas para un desarrollo coordinado de actuaciones en materias de combustibles gaseosos (art. 1.2 y art. 61) ${ }^{14 \mathrm{y} 15}$.

12 En materia de tráfico, la STS de 11 de diciembre de 1986 (RA 8104/1986), al manifestar en su Fundamento de Derecho Cuarto que «no habiendo más remedio que reconocer competencias a los respectivos Ayuntamientos", utiliza una expresión poco afortunada por cuanto parece defender más bien la regla general de no reconocimiento de competencias, salvo cuando no haya más remedio debe reconocérselas, como es el caso que ocupa esta sentencia en relación con las travesias.

13 Vid. STS de 28 de mayo de 1991 (RA 4298/1991), sobre abastecimiento de aguas por municipio e intervención concurrente de la Diputación Provincial.

14 En lo referente a carburantes, la STS de 16 de septiembre de 1993 (RA 6530/1993), en relación con un acuerdo de un Ayuntamiento de municipalizar sin monopolio la venta y distribución de carburantes decía: «El acto administrativo a que se refiere el presente proceso es un acuerdo del Ayuntamiento de municipalización sin monopolio de la venta y distribución de carburantes en el término municipal, a raíz de la cual se aprobó la constitución de una empresa mixta entre el Ayuntamiento y CAMPSA... Dos consideraciones ... Está reconocido pacíficamente en nuestro Derecho que el servicio de distribución y venta de carburantes es un servicio público... Segundo ... La prestación de este servicio eventualmente por el Ayuntamiento deberia hacerse en el marco de las competencias municipales...

En nuestro Derecho, la LBRL mantiene en su art. 25 la vieja cláusula de competencia general, según la cual el Municipio es competente para gestionar los intereses locales y promover toda clase de actividades y servicios que satisfagan las necesidades y aspiraciones de la comunidad. Pero dicha cláusula ha de entenderse en el contexto del sistema complejo (la cursiva es mía) que establece la ley, de acuerdo con la doctrina del TC y el TS...

Salvo en la estricta materia de servicios municipales minimos, en los demás casos no puede actuar el municipio si existe una competencia del Estado o de las CC.AA. que implica la titularidad del servicio público... Viniendo al presente supuesto el caso es que el Decreto-Ley 5/1985, de 12 de diciembre, puesto en relación con el Reglamento de Suministro y venta de carburantes del 5 de marzo de 1970, consagra inequivocamente el carácter de esta actividad como servicio público de titularidad estatal. Por tanto, el Ayuntamiento no puede válidamente adoptar un acuerdo de municipalización de un servicio público del que no es titular. En consecuencia, el acuerdo de municipalización es nulo de pleno Derecho a tenor del 
- Abastos, Mataderos y Mercados. Ley 26/1984, de 19 de julio, general para la defensa de los consumidores y usuarios (art. 28.2 y 41.1 y 3); Ley 14/1986, General de Sanidad; RD 1010/1985, de 5 de junio, de Venta Ambulante; Ley 26/1991, de 21 de noviembre, de Ventas a domicilio, en medios de transporte público, y, en general, contratos fuera de establecimientos mercantiles ${ }^{16}$.

- Radiodifusión Sonora. Ley 31/1987, de 18 de diciembre, de ordenación de las telecomunicaciones; Ley 11/1991, de 8 de abril, que establece normas sobre organización y control de las emisoras municipales de radiodifusión sonora.

- Ordenación del Territorio y Urbanismo. RD Legislativo 1/1992, de 26 de junio, Texto Refundido de la Ley sobre Régimen del Suelo y Ordenación Urbana ${ }^{17}$.

- Servicios Sociales. Ley de 14 de mayo de 1852, General de Beneficencia, en relación con la disposición final 2. ${ }^{\mathrm{a}}-4$ de la Ley General de Sanidad.

- Matrimonios Civiles. Ley 35/1994, de 23 de diciembre, de modificación del Código Civil en materia de autorización del matrimonio civil por los Alcaldes.

art. 47.l.a) de la Ley de Procedimiento Administrativo y lo es también la creación de la empresa mixtas.

is Sobre este tema, J. TORNo MAS, «Competencias municipales para la ordenación y gestión de los servicios públicos; especial referencia al suministro de agua, gas y electricidad", Revista de Estudios de la Admón. Local y Autonómica, . $^{\circ} 245$.

16 En relación con la extralimitación competencial municipal en materia de salubridad pública, vid., a modo de ejemplo, la STS de 12 de junio de 1993 (RA 4343/1993), que manifestaba que ula prohibición (a través de Ordenanza) de que los carteles y vallas contengan publicidad sobre el tabaco y bebidas alcohólicas en el término de Getafe desborda el ámbito de la protección de la salubridad pública municipal".

Un ejemplo de inexistencia de extralimitación competencial local lo encontramos en la STS de 15 de junio de 1992 (RA 5378/1992) sobre la declaración de ser conforme a Derecho una Ordenanza Municipal que establecía determinados controles sanitarios. La verdadera crítica viene por el hecho de limitar la actuación municipal a unos meros «controles» sin facultades decisorias realmente importantes. En esta idea profundizaremos más adelante.

17 A mayor abundamiento, vid. STC 56/1986 y la interesante STS de 21 de febrero de 1994 en relación con el control de la Comunidad Autónoma sobre la competencia municipal en materia de planeamiento.

De gran claridad expositiva resulta en este tema A. VeRDÚ MIRA, «El urbanismo como competencia de los entes públicos territoriales", $R D U, \mathrm{n}^{\circ} 131$ y $132,1993$.

En todo caso hay que tener en cuenta la reciente sentencia del Tribunal Constitucional de 20 de marzo de 1997 en cuanto a la declaración de inconstitucionalidad de la mayor parte de sus preceptos. 
- Carreteras. Ley 25/1988, de 29 de julio, de Carreteras y RD 1812/1994, de 2 de septiembre, por el que se aprueba el Reglamento General de Carreteras.

- Etc... ${ }^{18 y 19}$.

Del conjunto de disposiciones generales que hemos enumerado, podemos determinar unas conclusiones que reflejan el diferente posicionamiento y el diferente grado de atribución competencial que se ha dado a los entes locales por el legislador sectorial, estatal o autonómico; estas conclusiones son las siguientes:

1. No existe un tratamiento unitario por la legislación sectorial a la hora de determinar las competencias específicas de los entes locales, o lo que es lo mismo, hay legislación sectorial que regula una determinada competencia de forma prácticamente agotadora o exhaustiva, mientras que otra sólo reconoce una posibilidad genérica de actuación.

2. No todas se refieren al mismo ámbito de actuación. Así, mientras algunas otorgan a las entidades locales la posibilidad de completar esas competencias que se les reconocen, normalmente en virtud de su potestad reglamentaria, otras sólo se refieren a competencias o facultades de ejecución.

3. Existe la coincidencia de gran parte de esta legislación de atribuir a los entes locales muchas, pero a su vez improductivas competencias de inspección, fiscalización y control, con lo que, prácticamente, dejan a los entes locales atados de pies y manos en funciones tan importantes como planificación y gestión propias, y con el agravante de que en caso de que suceda cualquier cuestión relacionada con el tema que se trata, se facilita la «culpabilidad» del ente local por no haber inspeccionado o controlado.

4. No obstante, sí es positivo el que, en mayor o menor medida, se tenga en cuenta a los entes locales en la legislación sectorial, sin perjuicio de que, en determinados sectores de actividad, también el olvido sea importante.

5. Destaca sobremanera las competencias que la legislación sectorial atribuye a los municipios frente a las provincias, justificado, probablemente, por las genéricas competencias que la LBRL atribuye a éstas.

18 A modo de ejemplo de pronunciamientos jurisprudenciales sobre otra materia, vid. STS de 3 de mayo de 1991 (RA 4315/1991), sobre el servicio público de teléfono.

19 Especial protagonismo está adquiriendo la preocupación de los entes locales por el medio ambiente. A tal efecto puede estudiarse, entre otros, J. DOMPER FERRANDo, «Las competencias de las entidades locales en materia de medio ambiente", Revista de Estudios de la Admón. Local y Autonómica, n. ${ }^{\circ} 252$. 
6. Como consecuencia de la proliferación de legislación sectorial que limita la actuación municipal a la ejecución de normas o directrices de los entes territoriales superiores se está produciendo un secamiento competencial de éstas frente a los restantes entes territoriales, quienes, entre ellos mismos, combaten por la acaparación máxima de competencias.

7. La atribución de distinto grado de competencias entre los entes territoriales está produciendo en la práctica una multiplicación, a veces innecesaria, de oficinas y órganos con semejantes funciones. Así, como explicaba el profesor SOSA WAGNER no es infrecuente encontrar en el mismo municipio o ciudad, por ejemplo, una Delegación Provincial del Ministerio de Asuntos Sociales, en la misma acera una Delegación Provincial de la Consejería de Asuntos Sociales, en frente el Departamento de la Diputación Provincial de Servicios Sociales y junto a ella, la Concejalía de Servicios Sociales del Ayuntamiento correspondiente.

8. Habría que entender que no se trata de dotar a los Entes locales de muchas competencias por la legislación sectorial, tanto en cantidad como en calidad, ni tampoco se puede establecer un régimen unívoco para todos los Entes locales. Se trataría de otorgar aquellas competencias que afectando a los entes locales territoriales pueden y deban ser asumidas por ellos y, para aquellos que no pueden hacerlo, establecer el régimen obligatorio de implantación por las Diputaciones Provinciales. No aplicaríamos la fórmula «lo mismo para todos», sino «a cada uno lo suyo», que sería la fórmula de plasmar el principio de igualdad mediante el axioma de «tratar de forma desigual a los desiguales». ¿En qué cabeza cabe la posibilidad de unificar las competencias de una gran ciudad con las de un municipio que no alcanza los dos mil habitantes? Pero la dificultad, de muy compleja solución, está en el establecimiento de fronteras para delimitar esas competencias. ¿Qué criterios se utilizarían, el número de habitantes del Municipio o la Provincia?; ¿hasta qué número?; ¿su presupuesto?; ¿hasta qué cuantía?

9. La indefinición de las competencias locales por alguna legislación específica sectorial, si bien es criticable, tiene también, como aspecto positivo, el que permita un cierto laissez faire municipal y provincial que no se ve en principio recortado y cuya limitación termina la más de las veces en los tribunales de lo contencioso-administrativo.

10. Las leyes sectoriales de las CC.AA. tienen que asumir un papel predominante en la atribución de competencias a los entes locales mediante la legislación sectorial. Esta atribución puede provocar un desequilibrio en el posicionamiento de la Provincia, básicamente por la oposición de las CC.AA. de perder competencias en favor de aquélla y por aquéllas de garantizar su propia 
existencia vital mediante la atribución de competencias por las leyes autonómicas.

La pregunta es inminente. ¿Cómo garantizar en tales casos la autonomía local? ¿Cómo garantizar el derecho a la tutela judicial efectiva de las entidades locales? ¿Cómo garantizar el derecho racional de las entidades locales ante estas situaciones en que sus competencias pueden quedar sustraídas a nivel de disposiciones legales? ${ }^{20}$. Manifiesta el profesor LOPEZ GONZÁLEZ que las vías sólo pueden ser dos:

1. El procedimiento complejo del art. 63.3, en relación con el 119 de la LBRL, que posibilita el dirigir la pretensión a la Comisión Nacional de Administración Local para que ésta solicite de algún órgano constitucional legitimado la interposición del correspondiente recurso de inconstitucionalidad.

2. La vía que califica este autor como indirecta sería instar de los tribunales contencioso-administrativos el correspondiente proceso de cuestión de insconstitucionalidad con ocasión de la ejecución de algún acto en aplicación de estas disposiciones legislativas.

\section{EL PRESENTE Y EL FUTURO DE LAS COMPETENCIAS LOCALES: UNA DIFÍCIL PREDICCIÓN ${ }^{21}$}

Intentar predecir el futuro de las competencias locales es tanto como intentar predecir la propia existencia vital de los Entes locales. Su virtualidad en la organización territorial del Estado, su configuración, el «rol» que de ellas se espera, depende del grado de las atribuciones o competencias que se les vayan reconociendo. Éste es sin duda un punto sobre el que reflexionar; 0 , por mejor decir, sobre el que ya se está reflexionando en lo que se conoce comúnmente como el «Pacto Local». Salvo los servicios mínimos que la propia LBRL les reconoce, todas las demás competencias «se les tienen que reconocer o atribuir por legislación sectorial». Nadie ha dudado hasta la fecha de la vigencia en términos globales de la LBRL y del régimen competencial que contiene. Sin embargo, sí se echa en falta la ampliación de competencias, sobre todo municipales, a otros ámbitos de la vida pública que en el

20 Seguimos en este punto al profesor LOPEZ GONZÁLEZ en su argumentación expositiva realizada en Huelva, en 1994, durante unas jornadas de estudio de la Ley 30/1992, de 26 de noviembre, del Régimen Juridico de las Administraciones Públicas y del Procedimiento Administrativo Común.

21 Sobre este tema fue interesante el artículo de T. CUADRA-SAlCEDO FERNÁNDEZ DEL CASTILLO, «Pasado, presente y futuro de las Corporaciones Locales», Revista de Estudios de la Admón. Local y Autonómica, n. ${ }^{\circ} 241$. 
año 1985 no se consideraron de «interés local», pero que día a día los municipios y provincias demandan. Baste, por ejemplo, la especial problemática que se está planteando en relación con el tema de la intervención de las Corporaciones Locales en el apoyo y en el fomento del empleo, y la especial problemática del posicionamiento municipal ante el consumo de drogas en vía pública que tanto preocupa a la ciudadanía. Con respecto al primer tema, el fomento del empleo, la acción municipal en esta materia viene recogida en el art. 86 de la Ley de Bases y dentro del capítulo dedicado a actividades y servicios, donde, para dar pragmatismo al art. 128.2 de la Constitución Española, se admite la posibilidad de que las Entidades locales puedan intervenir en el ejercicio de actividades económicas mediante el correspondiente expediente. acreditativo de la conveniencia y oportunidad de la medida.

Sin embargo, como expresa P. A. MARTíN PéreZ, en un artículo publicado en la revista La Ley en 1994, "el art. 27 de la Ley de Bases regula la delegación de competencias de la Administración del Estado y de las Comunidades Autónomas a los Municipios, siempre que incidan de una manera positiva en la satisfacción de los intereses propios del Municipio. Dichas delegaciones, de una manera específica y respecto a competencias en materia de apoyo al empleo, no se han producido».

De tal forma que frente a una declaración de voluntad de intervención decidida por parte de los Municipios sólo le quedan unos mecanismos intermedios pocos resolutorios para participar en estas medidas de fomento de empleo, como son, por ejemplo, las solicitudes de subvenciones al Fondo Social Europeo o la intervención en proyectos de iniciativas locales de empleo, así como la última «moda» de crear unidades de promoción de empleo o unidades básicas de iniciativa económica con el fin de dinamizar la actividad económica del municipio.

En lo que se refiere a la problemática del consumo de drogas en las vías públicas, y siguiendo también al mismo autor, coincidimos con él en el sentido de que «no cabe la menor duda en los tiempos que corremos que los Municipios, que los Ayuntamientos, intervienen en todos los niveles que afectan a la vida del ciudadano y a veces acometen competencias de actividades que antes se encontraban reservadas a otras Administraciones Públicas, y que por falta de medios o inercia de éstas, entre la demanda y la reivindicación ciudadana, han sido desarrolladas por los mismos municipios, esto, no obstante, algunas veces el estado depauperado de las arcas municipales». Sin embargo, coincide este autor en la confirmación de los escasos medios jurídicos de que disponen los Entes locales para regularizar una materia que en principio es de competencia estatal. Pone como ejemplo el que determinados municipios han aprobado Ordenanzas prohibiendo y sancionando el consumo de drogas en la vía pública, 
como las Corporaciones de Toledo, Plasencia, Cartagena, etc., y se empieza a discutir la posibilidad de que por la Alcaldía-Presidencia se dicten bandos prohibiendo tales actuaciones. Sin embargo, el impedimento más importante lo encontramos al analizar Sentencias del TS, como la de 21 de julio de 1987, que establece que «el ámbito sancionador local debe ajustarse a los siguientes requisitos: a) Que exista una Ley; b) que la Ley sea anterior al hecho sancionador y c) que la Ley describa un supuesto de hecho estrictamente determinado». Al no tener las Ordenanzas Municipales carácter de Ley, y mucho menos los Bandos de los Alcaldes, es difícil realizar actuaciones preventivas o sancionadoras en esta materia por parte de los municipios.

Sirvan los anteriores ejemplos como botón de muestra de los cada vez mayores intereses locales en distintos sectores de actividad y que precisan una ampliación competencial de los municipios y provincias sobre los mismos, aún vírgenes en muchos aspectos.

Por lo que respecta a la Provincia, evidentemente hemos de centrarnos en dos grandes problemas que han generado, a su vez, un tercero. En primer lugar, la indefinición de competencias que se atribuye a la Provincia y en segundo lugar la falta de adecuación por la legislación específica sectorial posterior al nuevo planteamiento y distribución de competencias de las Diputaciones Provinciales efectuadas desde el Texto Constitucional y la Ley de Bases de Régimen Local. Ambos problemas han provocado un tercero, cual es la concurrencia de competencias entre diversos entes territoriales y las lógicas tensiones competenciales.

Sin embargo, no debe desconocerse a las Diputaciones Provinciales su papel decisivo en la gestión de servicios que resulta absolutamente inaccesible a los pequeños municipios, aunque, sensu contrario, existen opiniones doctrinales contrarias, o al menos críticas, al provincialismo que abogan por la regionalización a nivel comarcal, mancomunidades de municipios o áreas metropolitanas y un debilitamiento progresivo, e incluso se habla de desaparición, de la Provincia. Sin duda, las Diputaciones Provinciales de nuestro entorno geográfico no pueden asumir con eficacia sus propias competencias si no se potencian los pequeños y medianos municipios mediante el fomento de la fórmula asociativa que supone la creación de mancomunidades que presten integralmente los servicios municipales a un costo razonable y con un mayor grado de eficacia mediante el incremento de sus medios personales y materiales. En lo que respecta a las Diputaciones Provinciales podemos hacer las siguientes predicciones. Así, a corto plazo:

- Una revisión y modificación de la Ley de Haciendas Locales, propiciando una flexibilización del sistema tributario y una actualización de los criterios de distribución del fondo de participación en los ingresos del Estado. 
DIVERSAS CONSIDERACIONES SOBRE LAS COMPETENCLAS LOCALES

- El establecimiento de convenios de gestión de competencias residuales, especialmente en sanidad, así como en servicios sociales y atención a poblaciones marginadas.

- Un plan de saneamiento financiero y planes de control presupuestario y exigible a todas las Corporaciones Locales.

- Planes de mejora en los servicios de recaudación y gestión tributaria municipal y supramunicipal.

- Planes de formación y especialización de los servicios técnicos y gerenciales de las Corporaciones Locales, que son manifiestamente insuficientes.

A medio plazo:

- La redefinición del marco de competencias atribuidas a las Diputaciones Provinciales en desarrollo de sus funciones básicas de asesoramiento, de asistencia y colaboración con los Municipios de menor capacidad económica y de gestión, asumiendo competencias de planificación y coordinación de las actividades que tanto el Estado como la Comunidad Autónoma ejercitan en el ámbito provincial.

- Descentralización de competencias de las Comunidades Autónomas en favor de las Diputaciones como medios más eficaces para prestación de servicios, acercando éstos a la esfera de los municipios y de los ciudadanos.

- Desarrollo por las Comunidades Autónomas de la legislación básica de régimen local, fomentando las mancomunidades de Municipios y clarificando la compleja situación de las Entidades locales de ámbito territorial inframunicipal en su relación con el Ayuntamiento del que dependan.

Y a largo plazo la adopción de las siguiente medidas:

- La revisión de las disfuncionalidades que se produzcan como consecuencia de la puesta en práctica de la propuesta efectuada mediante acuerdos de política municipal y provincial a nivel nacional, lo que sería en definitiva desarrollar el Título VIII de nuestra Constitución.

- Distinguir entre los problemas estructurales y los coyunturales y marcar un calendario factible a través de unos pasos progresivos, abordable desde la convicción constitucional y desde un generoso entendimiento con la totalidad de las fuerzas políticas. 
La realidad competencial de los entes locales es criticable por la existencia de un cierto descontrol o la realización de actuaciones, atendiéndose a auténticas «modas». Así, a comienzos de los años 90 , ha sido muy frecuente la eclosión de patronatos y empresas municipales, mediante la utilización de distintas tipologías societarias, que se han realizado sin estudios serios económicos, de gestión y financieros, para poder desarrollar las actividades que se pretendían, lo que ha provocado que gran número de ellas sean prácticamente inoperativas, todo ello bajo la pretendida huida del Derecho Administrativo.

También podemos hablar de las tendencias de las Corporaciones Locales de asumir cada vez mayor nivel competencial en aras a la actividad positiva de generación de empleo, fomento de la economía, y desarrollo socio-económico de la población, lo que supone un salto cualitativo respecto a una visión tradicional y arcaica de los entes locales como embalses estancados de competencias no productivas. Sin duda, el desarrollo competencial de los entes locales debe pasar por el fenómeno del asociacionismo, como hemos visto con anterioridad, otorgando un papel importante a la comarca que precisará de un desarrollo legislativo completo, así como las áreas metropolitanas y las mancomunidades de municipios.

Todo este conjunto de competencias, que deberán ir asumiendo las Corporaciones Locales y que el legislador deberá arbitrar mediante una legislación correcta y adecuada, aunque seguramente no pacífica, va a provocar la continuidad de las tensiones competenciales entre Municipios y Provincias y Comunidades Autónomas sobre todo. No sería osado decir, sobre todo en lo que respecta a la Provincia, que las tensiones versarán sobre aquellos que consideran que las atribuciones o competencias provinciales deben ser subsumidas por las propias Comunidades Autónomas y, por lo tanto, desaparecer mientras que otros considerarán que debe potenciarse el papel de la Provincia sobremanera para garantizar los servicios en los pequeños municipios, sin olvidar que también sería conveniente retomar aquella vieja idea de supresión de pequeños términos municipales insignificantes en cuanto a población y nulos en cuanto a gestión de servicios o competencias propias por su escasez de medios personales, materiales y económicos.

\section{CONSIDERACIONES PRÁCTICAS DE LA LABOR JURISDICCIONAL ANTE CONFLICTOS POR EJERCICIO DE COMPETENCIAS LOCALES}

Pero ante toda esta problemática lo que sí va a resultar verdaderamente práctico, y ya las STS y STC nos han puesto en antecedente sobre ello, es analizar qué labor deductiva debe realizar el operador jurídico para dirimir cuándo 
una competencia realizada por un ente local excede del ámbito competencial propio o no excede del mismo, y por tanto, procedería declarar a intuir la nulidad del acto administrativo o la disposición reglamentaria que fundamentara o que sostuviera ese ejercicio competencial. Ante todo, esta labor debe calificarse como «compleja».

No se trata de comprobar la aplicación correcta, incorrecta o no aplicación de un precepto legal o reglamentario. Se trata de realizar una labor de sintesis de ideas y principios jurídicos jurisprudencial y doctrinalmente reconocidos y aplicarlos a un supuesto de hecho concreto sin olvidar, claro está, la literalidad de los preceptos discutidos.

El proceso que debe seguir el órgano jurisdiccional para enjuiciar la existencia o no de una competencia local en un acto administrativo o disposición reglamentaria emanada de los Entes locales debería ser el siguiente ${ }^{22}$ :

1. Utilizar como primera base de argumentación jurídica el criterio del «interés respectivo» (STC 4/1981, de 2 de febrero) para una definición positiva y negativa de la autonomía local. Positiva: la autonomía local significa un derecho de la comunidad local a la participación en el gobierno y administración de cuantos asuntos le atafien, graduándose la intensidad de esa participación en función de la relación entre intereses locales y supralocales dentro de las materias o asuntos de que se trate. Negativa: la autonomía no se garantiza en la CE para incidir de forma negativa sobre los intereses generales de la nación o sobre otros intereses generales distintos de los propios de la Entidad local. Es claro que los intereses nacionales y autonómicos prevalecen, en caso de conflicto, sobre el interés local.

En definitiva, el interés respectivo ha de entenderse en el contexto del sistema complejo que establece la Ley, de acuerdo con la doctrina del TC y del TS (STS de 16 de septiembre de 1993), con la aclaración de que el interés supralocal predomina sobre el interés local (STC 170/1989, de 19 de octubre).

2. Delimitado el interés respectivo, debe, a continuación, analizarse si la competencia sobre la materia es exclusiva o no del Estado o de la Comunidad Autónoma, de acuerdo con la Constitución y la legislación sectorial aplicable. $\mathrm{Si}$ así fuera, el acto administrativo o disposición reglamentaria local sería nulo de pleno derecho por vicio legal de incompetencia (STS de 30 de abril de 1986, 13 de junio de 1986; 21 de julio de 1986; 3 de noviembre de 1986; 9 y 17 de febrero de 1987 y 3 de febrero de 1988). El mismo criterio se desprende

22 Evidentemente, los conflictos de competencias vendrán siempre bien por parte del Estado, bien por parte de la CA respectiva. 
de la STC 56/1986, de 13 de mayo. En todo caso, encontraríamos intereses locales que justificarían el ejercicio de competencias por estos entes en los supuestos de los arts. 25,26 y $36 \mathrm{LBRL}$, sin perjuicio de las que les asigne la legislación sectorial.

3. En el supuesto de que concurran varias Administraciones en el ejercicio de competencias legalmente atribuidas debe comprobarse si la Administración que ha actuado (en nuestro caso, la local) ha ponderado adecuadamente, en el ejercicio de sus competencias propias, la totalidad de los intereses públicos implicados.

4. De la normativa contenida en la Carta Europea de la Autonomía Local de 15 de octubre de 1985 se deduce que (art. 8.2):

a) Es lícito un control de la actuación de los Entes locales para asegurar el respeto a la legalidad y a los principios constitucionales.

b) Cabe también un control de oportunidad «respecto a competencias cuya ejecución se haya delegado en la Entidad local», ámbito este de la delegación que ha de extenderse a los supuestos de competencias compartidas, dado que en ella, junto a los intereses locales y en clara conexión con éstos, pueden aparecer intereses supralocales.

5. La conexión de los intereses locales y supralocales precisan de una concreción para poder analizar, como ejemplo clásico, la extensión del control de la Comunidad Autónoma en las aprobaciones definitivas de planeamiento urbanístico, y que podrán hacerse extensivos a otros ámbitos competenciales. Así:

a) Aspectos reglados del plan: Control pleno de la Comunidad con una matización para el supuesto de que entren en juego conceptos jurídicos indeterminados:

- Si la determinación del planeamiento no incide en aspectos de interés supralocal, el margen de apreciación que tales conceptos implica corresponde a la Administración municipal.

- Si el punto ordenado por el plan afecta a intereses superiores, ese margen de apreciación se atribuye a la Comunidad.

b) Aspectos discrecionales. Subdistinción:

- Determinaciones del plan que no inciden en materias de interés autonómico: 
DIVERSAS CONSIDERACIONES SOBRE LAS COMPETENCIAS LOCALES

- Serán viables los controles tendentes a evitar la vulneración de las exigencias del principio de interdicción de la arbitrariedad de los poderes públicos (SSTS de 20 de marzo, 30 de abril y 4 de mayo de 1990).

- No serán en cambio admisibles revisiones de pura oportunidad.

- Determinaciones del plan que tienen conexión con algún aspecto de un modelo territorial superior: Además de ser viables los controles tendentes a evitar la vulneración de las exigencias del principio de interdicción de la arbitrariedad de los poderes públicos, dado el predominio del interés supralocal sobre el local, resulta admisible un control de oportunidad en el que prevalece la apreciación comunitaria (SSTS de 30 de enero, 25 de abril de 1991 y 18 de mayo de 1991).

6. Finalmente, en caso de extralimitación competencial, debe proceder a declarar la nulidad de pleno Derecho del acto administrativo local o disposición reglamentaria en discordia. Si no considera que exista extralimitación competencial declarará ajustado a Derecho el acto disposición, y a partir de esa declaración, de obligado cumplimiento, respetando su ejercicio por el ente local, para el Estado y las CC.AA. 
